Reseña

\title{
Mateus, Samuel. (2021). Discurso Mediático. Covilhã: Universidade da Beira Interior.
}

\author{
José Antonio Abreu Colombri ${ }^{1}$ ORCID: 0000-0002-8698-6493 \\ ${ }^{1}$ Universidad de Alcalá.
}

El estudio de los discursos mediáticos actuales está muy fragmentado, porque la gran diversidad de contenidos comunicativos y la creciente presencia de espacios mediáticos complican mucho la creación de un marco de trabajo amplio y definido. Los investigadores de las ciencias de la comunicación no suelen abordar el estudio de los discursos de forma global. Por este principal motivo, el profesor Samuel Mateus[1] realizar un gran esfuerzo de investigación, que ha cristalizado en una publicación ambiciosa, digno de ser reconocido académicamente.

El libro, Discurso Mediático, se compone del prefacio, la introducción, dos bloques temáticos, la conclusión y un apartado de referencias bibliográficos. El primer bloque temático, Teoría, se compone de cuatro capítulos, destinados a la reflexión de los usos sociales del lenguaje, la diversidad sociocultural de los discursos y la funcionalidad de los soportes comunicativos. El segundo bloque temático, Empiria, presenta varios casos de estudio (capítulos quintos y sexto) sobre los modelos discursivos, la estructura narrativa de los discursos mediáticos y las estrategias de difusión de los mensajes interactivos. La dimensión social del diseño de los discursos es transversal en toda la publicación, un factor muy presente en casi todas las líneas de investigación de la plataforma LabCom[2].

El prefacio es obra el profesor Adriano Duarte Rodrigues (catedrático honorífico de la Facultad de Ciencias Sociales y Humanas de la Universidade Nova de Lisboa). En estas páginas se hace una presentación teórica de los objetivos de la 
investigación del autor, en clave histórica, llevando a cabo una puesta en valor de la compilación temática de la obra en su conjunto. La introducción se centra en el proceso de realización de un análisis de los discursos mediáticos, el planteamiento conceptual del análisis crítico, los objetivos primarios de la investigación y el sentido pedagógico del diseño de la publicación.

El primer capítulo, O Discurso como Práctica Social, contiene los elementos más teoréticos y funcionales de las prácticas discursivas en las sociedades contemporáneas: usos del lenguaje, influencia social, interacción comunicativa, definiciones de discurso, proceso de creación, soportes de difusión y prácticas de interacción socio-cultural. Los discursos se integran en el proceso de creación cultural de forma significativa, dichos discursos trascienden en el plano textual y en otros soportes hemerográficos, que acaban convirtiéndose en conocimiento sedimentario para las nuevas generaciones de autores.

O Discurso Mediático es el título del segundo capítulo. En estas páginas se desarrollan temas como la conformación de las maquinarias discursivas, las coyunturas mediáticas, la naturaleza del discurso, las funciones del discurso (referencial y fáctica), la interacción de los agentes discursivos, la simbiosis de los elementos socio-culturales del discurso, los principios del funcionamiento estratégico y los marcos enunciativos de discurso mediático. El autor trata de argumentar, en líneas generales, por qué es interesante el estudio de los modelos discursivos. En la parte final, se presentan varios argumentos para describir el condicionamiento ambiental de los medios de comunicación sobre los sujetos discursivos.

El tercer capítulo, Princípios Fundamentais do Discurso Mediático: a Intertextualidades e a Multimodalidade, constituye el conjunto de epígrafes más multidisciplinares y polimorfos del libro. El autor sostiene que los aspectos intertextuales y los efectos multicausales componen los principios más elementales del proceso discursivo en su dimensión mediática: polifonías, dialogismos, importancia funcional de los hipertextos, rol inclusivo de los soportes, nexos extensivos del mensaje comunicativo y tipología básica del concepto de intertextualidad. Algo muy similar sucede con los tipos elementales 
de modelos de discursos diseñados para ser proyectados en medios de comunicación.

Este conjunto de principios tiene una gran trascendencia en el lenguaje y en la simbología de los anuncios publicitarios. Para el autor, todos estos planteamientos acaban convergiendo en la perspectiva de la investigación semiótica. El cuarto capítulo supone la finalización lógica del primer bloque temática de la obra: $O$ Discurso Mediático: Publicidade e Imprensa. En este caso, el análisis de la publicidad y la empresa periodística es bastante dinámico. Las identidades simbólicas se convierten en la columna maestra de la construcción del discurso publicitario, mientras que los objetivos comerciales establecen las prioridades del diseño del modelo publicitario.

El quinto capítulo lleva por título Análise do Discurso Mediático. En estos apartados se presentan algunas líneas básicas para comenzar un proyecto de análisis para los discursos construidos por los medios de comunicación. Consiguientemente, el autor realiza una propuesta metodológica, para establecer marcos analíticos del discurso mediático como concepto y como objeto de estudio:

1) Condicionantes de la producción y la recepción;

2) Análisis visual del texto;

3) Análisis lingüístico del texto;

4) Estrategias discursivas. Cualquier planteamiento metodológico debe establecer cuáles son los rasgos generales y clasificar cuáles son las variantes más pronunciadas.

La definición de identidades y la identificación de las interacciones sociales son claves para delimitar el área de estudio del ámbito discursivo.

Analisando Textos Mediáticos es el título del sexto y último capítulo. El autor considera que la realización de un buen análisis requiere establecer con precisión los condicionantes del proceso de creación de discursos, examinar el contexto visual del texto, sintetizar los elementos clave del lenguaje textual $y$, pormenorizadamente, clasificar las estrategias que condicionan la implementación de la actividad discursiva. Las nuevas dinámicas digitales, desde el punto de vista 
del autor, son claves para comprender las grandes transformaciones del discurso en todos los contextos de la comunicación social. El texto mediático representa dos discursos: el discurso visual y el discurso lingüístico. Ambos suelen complementarse, pero rara vez suelen ser plenamente coincidentes.

El análisis del discurso mediático, desde diferentes enfoques teóricos, demuestra que un mismo texto puede contener elementos informativos diferentes. Entre esas diferencias, pueden aparecer mensajes complejos que tensionan la significación final del discurso. La significación final depende directamente de la interpretación inicial de los lenguajes textuales y visuales. El autor plantea muchos ejemplos extractados del panorama mediático de Portugal, aunque también utiliza recursos publicitarios y periodísticos de carácter global. De forma concluyente, se puede afirmar que el libro tiene un desarrollo temático sucinto y riguroso, que determina todas las claves teóricas del análisis del discurso mediático y que puede coadyuvar a cualquier joven investigador de las ciencias de la comunicación.

\section{Referencias bibliográficas}

Mateus, Samuel. (2021). Discurso Mediático. Covilhã: Universidade da Beira Interior.

\section{Notas}

[1] Obtuvo sus estudios de grado y posgrado (máster y doctorado) en la Universidade Nova de Lisboa. En la actualidad, es profesor de la Universidade de Madeira y director de la Unidad Curricular de Análisis de Discurso Mediátio. También forma parte de la plataforma de investigación LabCom, en la Universidade da Beira Interior. La mayoría de sus publicaciones están relacionadas con las áreas temáticas de la teoría de la información periodística, los modelos discursivos y publicitarios y la historia del periodismo en Portugal.

[2] La Universidade da Beira Interior, situada en la subregión de Beiras y Serra da Estrela, es una institución de la red de centros de educación superior de la República de Portugal. En 1973, durante la fase final de la dictadura militar, se creó el Instituto Politécnico de Covilhã. En 1979, dicho instituto se refundó y se 
constituyó el actual centro universitario, como parte de un ambicioso plan de desarrollo educativo en las áreas rurales. El campus de Covilhã es muy sincrético, ya que reutilizar espacios arquitectónicos muy diversos, que van desde estructuras civiles y militares de la era preindustrial hasta una fábrica textil contemporánea.

\section{Nota del editor}

La presente reseña fue aprobada para su publicación por el Dr. Prof. Mario Barité.

\section{Nota de contribución autoral}

La reseña ha sido elaborada solo por mí. Los contenidos del texto son descriptivos mayoritariamente. No tengo relación con el autor del libro reseñado, mi interés viene dado por el tema de libro y la editorial, ya que estuve realizando una estancia de investigación en la Universidade da Beira Interior (2019-2020). 